\title{
Self-perceived body image and body satisfaction of adolescents
}

\author{
Maraísa I. C. Justino 1 \\ iD https://orcid.org/0000.0002-0963-1381 \\ Carla Cristina Enes 2 \\ (iD) https://orcid.org/0000-0002-4634-4402 \\ Luciana Bertoldi Nucci 3 \\ https://orcid.org/0000-0002-5140-3622
}

1-3 Programa de Pós-Graduação em Ciências da Saúde. Centro de Ciências da Vida. Pontifícia Universidade Católica de Campinas (PUC-Campinas). Av. John Boyd Dunlop, s.n. Jardim Ipaussurama. Campinas, São Paulo, SP, Brazil. CEP: 13.060-904. E-mail: cacenes@gmail.com

\begin{abstract}
Objectives: to evaluate self-perceived body image and body satisfaction of adolescents and their associated factors.

Methods: across-sectional study carried out with 200 adolescents from a non-governmental organization of Campinas-SP. Self-perceived body image was assessed using a scale of silhouettes and body satisfaction by body areas. Association between sociodemographic and anthropometric data and body image and satisfaction were assessed by logistic regression.

Results: seventy percent of normal weight boys and $88 \%$ of girls wrongly perceived their nutritional status according to the objective standards. The prevalence of body dissatisfaction was $76.5 \%$. Twenty-two percent of adolescents reported dissatisfaction with their body shape. Self-perceived body image was associated with nutritional status (OR=0.25; $C 195 \%=0.09-0.73)$, abdominal obesity (Waist/Height ratio- WHR) $(O R=26.57 ; C 195 \%=3.98$ 177.18), and gender $(O R=2.65 ; C 195 \%=1.16-6.05)$.

Conclusions: we identified an important distortion and dissatisfaction with body shape. Girls, overweight/obese adolescents and those with abdominal obesity have more chance to this condition. These findings can subsidize actions that deal with the issue of acceptance of self-image, preventing more serious disorders that may directly affect the health of youngsters.
\end{abstract}

Key words Adolescent, Body image, Nutritional status

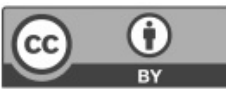




\section{Introduction}

Beauty has been extremely valued nowadays in society. In this context, anincrease in people's dissatisfaction with their own appearance, especially among women, has been identified. ${ }^{1}$

Body image is the figure that one has on their anthropometric measurements, contours, and shape of the body; and also the feelings correlated to these factors that affect the satisfaction with the body or specific parts of the body. ${ }^{2}$ It is a multidimensional construct surrounded by the sensations and immediate experiences, involving a subjective component. ${ }^{3}$ Several factors that influence body image can be derivate from physical, psychological, and/or environmental issue. Also, there are factors related to the characteristics of each individual, such as age and gender, and those that are subjective as media, beliefs and values. 4

Historically, the pattern of beauty has advanced as society evolves. The valued female body was already curvilinear and robust as of the Greek goddesses, for example. Paradoxically, at the present time, it is expected that they are lean bodies, slender and young like the models, even in Brazilian society. In contrast, for men, the constant search since ancient times is based on the athletic size and on being tall. In addition, broad shoulders, defined muscles and abdomen are expected5. These changes of stereotyped bodies that circulate frequently on social media, television, magazines, video games, clothing stores and even among families contribute to adolescent's unhealthy self-perception of his/her body. 4,5

In adolescence, defined chronologically by World Health Organization as the period from 10 to 19 years of age, concerns about body and appearance become even more intense. Physical, psychological and social changes can significantly affect eating habits and body self-perception. At the same time, media also plays an important role in adolescents' lives, encouraging the search for a perfect body, valuing thinness as a symbol of competence, success and sexual attraction. 5

Usually girls aspire to became thinner while boys tend to desire an athletic body shape. ${ }^{6}$ Incorrect recognition of body weight status as well as negative body image is a threat to weight control as it may be associated with unhealthy behaviors and psychosocial morbidities. 7

Studies showed a prevalence of body dissatisfaction, defined as the perception that body size is larger than desired, up to $90 \%$ in young adults. 8,9 The increase of body dissatisfaction was identified even between children and adolescents. In these group the percentage of dissatisfaction ranges from $20 \%$ to $60 \%$ depending on sex, ethnicity, socioeconomic status and nutritional status. 10,11

Body dissatisfaction often occurs among adolescents because of their transition period, which is characterized by rapid growth and development as well as continuous changes in their bodies. Youngstersdissatisfied with their body image commonly report more complaints of psychosocial health problems such as difficulty to sleep at night, feeling nervous, stressed or depressed, having low self-esteem and low quality of life. 12

Thus, it is believed that the prevalence of body dissatisfaction and body image distortion is high in this sample, especially since it is a population of high social vulnerability. Considering that body image may plays an important role in managing and maintaining a healthy body weight, the identification of factors associated to body image distortion can be crucial in promoting a healthy weight at this age. The aim of this study was to evaluate self-perceived body image and body satisfaction of adolescents and their associated factors.

\section{Methods}

We performed a cross-sectional analysis using data from a study entitled "Factors associated with occurrence of overweight and obesity in adolescents from Projeto Gente Nova (PROGEN, Campinas, SP)", with adolescents aged 10 to 18 years old, of both genders from a non-governmental organization of a large city in the interior of the state of São Paulo. The three project units are located in the northwest region of the municipality, recognized as an area of high social vulnerability, where lowincome families live. The organization has been in existence since 1984 and serves young people living nearby by offering occupational activities related to music, multimedia, circus, dance, theater, sports, workshops, education and citizenship and socioeducational workshops. Data collection was held between June 2016 and May 2017 by trained interviewers through standar-dized protocols. Data were obtained by a structured questionnaire with information on sociodemographic characteristics, sexual maturation, body image self-perception and body satisfaction.

A population of 526 adolescents aged 10 to 18 years old assisted by the project was considered, including the three units of the non-governmental organization (Unit I = 171, Unit II = 205 and Unit $\mathrm{III}=150$ ). To obtain the sample size a prevalence of 
overweight of $21 \%$ was considered, 13 from a similar sample to the present study, type I error of 5\% and type II error of $10 \%$, totalizing a minimum sample to be representative of the population of 172 adolescents. Considering the possible losses due to nonacceptance to participate in the research, the consent term was distributed to all adolescents $(n=526)$ and only 210 adolescents returned the term signed by the parents / guardians. However, 10 adolescents were not found in the units on the days of data collection and therefore did not participate in the survey. Thus, the final sample was of 200 adolescents. Figure 1 shows the study sample flowchart.

Adolescent's self-perceived body image were assessed by the scale of silhouettes created by Stunkard et al., 14 composed of nine figures and a score ranging from 1 , for the smallest body size, up to 9 , to the largest body size. This scale has been widely used in Brazilian studies investigating body satisfaction. 15 Adolescents were asked to indicate the figures that represented their actual body (named
"Me") and the figure of the body they wished to have (named "Ideal"). The magnitude of body dissatisfaction was measured by the difference between the score of the current body (I) and the desired body (Ideal). Values ranged from -8 to 8 , with positive values expressing an overestimated weight perception (desire to lose weight) and negative values expressing an underestimated weight perception (desire to gain weight). Any value different from zero represented body dissatisfaction and the value "zero" corresponded to satisfaction with the current body size.

Body satisfaction was assessed by body areas using the scale suggested by Brown et al.16 and adapted by Loland 17 that includes 12 body areas.

Response options ranged from 1 , very dissatisfied to 5 , very satisfied. We calculated the mean score (sum of the numbers indicated in each body area), and the higher the score, the greater the body satisfaction. Adolescents were divided into two categories regarding body satisfaction based on the

Figure 1

Sample flowchart.

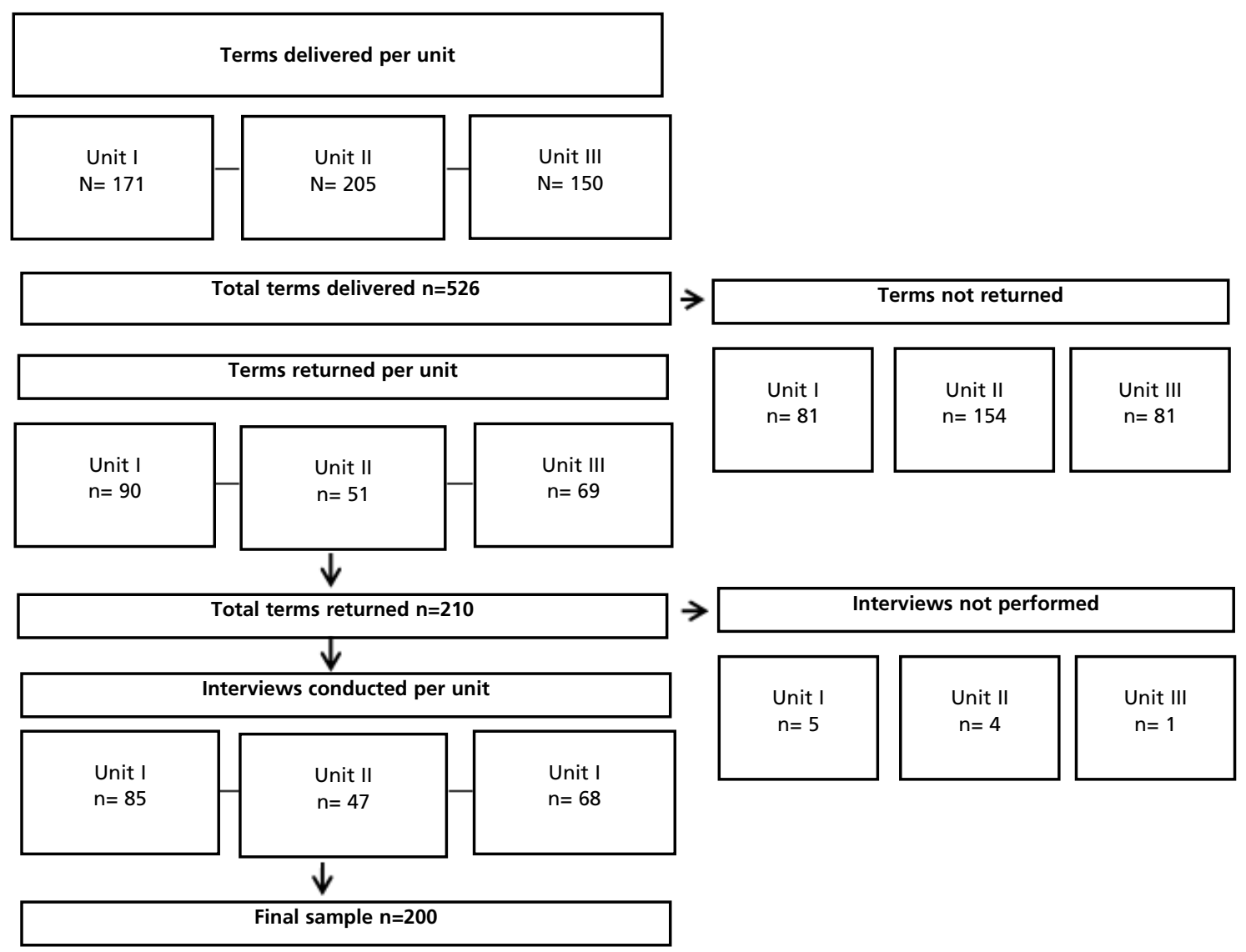


following criterion: "satisfied" when the mean score was higher than 45 and "dissatisfied" when the mean score was less than or equal to 45 .

Weight was measured using a digital scale $\left(\right.$ Balmak $^{\circledR}$ ) with a precision of $50 \mathrm{~g}$ with the adolescent wearing lightweight clothing and barefoot. Height was measured using a calibrated portable stadiometer (Alturexata ${ }^{\circledR}$ ) with a precision of $1 \mathrm{~mm}$, fixed on a flat surface (wall without baseboards). All anthropometric measures followed the procedures recommended in the Reference Manual for Standardization of Anthropometric Measures. ${ }^{18}$

Data from weight and height was used to calculate body mass index (BMI) $(\mathrm{BMI}=$ weight $[\mathrm{kg}] /$ heigh $\left.\left[\mathrm{m}^{2}\right]\right)$. Nutritional status was classified according to World Health Organization 19 reference curves for the attribution of BMI z-scores for age and gender. Cutoff values used were: $<Z$-score -2 for underweight; $\geq Z$-score -2 and $\leq Z$-score +1 for normal weigh; $>Z$-score +1 and $\leq Z$-score +2 for overweight; and $>Z+2$ score for obesity. Considering that only one individual presented underweight, and the value was very close to the limit of normal weight, he/she was grouped within the normal weight ones.

Abdominal obesity was evaluated by waist circumference (WC) and Waist / Height Ratio (WHR). WC was obtained from the waist line at the midpoint between the last rib and the iliac crest with the aid of a retractable inelastic tape of the brand TBW ${ }^{\circledR}$ with scale from 0 to $150 \mathrm{~cm}$. The cut-off point used for the classification of WC was the one proposed by Taylor et al.,20 which define abdominal obesity at risk as $\mathrm{WC} \geq 80^{\text {th }}$ percentile, adjusted for age and sex. Considering WHR, the criteria recommended by Li et al. ${ }^{21}$ were adopted, which suggests 0.5 as a cut-off point for the definition of abdominal obesity, risk values were above this cut-off point.

All anthropometric measures were performed in duplicate, using the mean value. In cases of many discrepant values, a third measure was performed.

The other variables assessed as covariates were age (in full years), gender, race/ethnicity (selfreported), sexual maturation and socioeconomic status. Sexual maturation was assessed by self-classification based on the proposal of Marshall and Tanner.22,23 Adolescents received figures to indicate, individually, their maturation's stage. These sexual maturation stages were grouped into three categories: pre-pubertal (stage I), pubertal (stages II, III, IV) and post-pubertal (stages V and VI).The socioeconomic classification was characterized using similar criteria used in the Brazilian census 24 which includes data regarding consumer goods and schooling of the head of the family. This instrument allows classifying the participant in A1, A2, B1, B2, $\mathrm{C} 1, \mathrm{C} 2, \mathrm{D}$ and $\mathrm{E}$ classes, in descending order of purchasing power. Classes D and $\mathrm{E}$ were grouped into one category and classes $\mathrm{C} 1$ and $\mathrm{B} 2$ were grouped into another category, due to low frequency.

Descriptive statistics were calculated and absolute and relative frequencies were estimated for the main anthropometric and body self-perception indicators. The chi-square test was used to verify the associations between body self-perception and degree of body satisfaction and other variables of interest. Multinomial logistic regression was used to explore the association between covariates and selfperceived body image, being the outcome variable "underestimated weight perception", overestimated weight perception" and "satisfied". The association between body satisfaction and covariates were investigated using binomial Logistic regression models with outcome variable "satisfied" and "dissatisfied". Variables of interest that presented $p$-values $<0.20$ in the crude models were maintained in the final model. Statistical analyzes were performed in software STATA 12 and SPSS v. 17 . Values of $p<0.05$ were considered statistically significant.

The consent form was given to all adolescents from the non-governmental organization, but only those who parent/guardian returned the agreement signed participated. Adolescents also signed the consent term. The study was approved by the ethics committee of Pontifical Catholic University of Campinas under the number 54866816.4.0000.5481, considering the terms set in resolution 466/2012 of the National Health Council.

\section{Results}

Girls accounted for $56 \%$ of the sample, the majority of adolescents were between 10 and 14 years old, most reported brown (42\%) skin color, and most came from families in the low $(\mathrm{C} 2)$ economic class (46.2\%). Excess of weight (overweight+obesity) was identified in $64.5 \%$ of adolescents and $78.5 \%$ presented no cardiovascular risk measured by abdominal obesity. Regarding sexual maturation, $88 \%$ were in the pubertal stage. Half of the girls had already menstruated, and the mean age of menarche was $11.4 \pm 1.1$ years (data not shown in table).

Figure 2 shows the distribution of self-perceived body image across nutritional status categories by gender. Among boys, we verified that approximately $66 \%$ of those who were of normal weight wished to gain weight indicating that boys perceived their body shape to be smaller than it really was, representing a 
self-image distortion. Adolescents with obesity were those who better recognize their body image (68.5\% desire to lose weight).

Among girls, 63.6\% with normal weight underestimated their actual nutritional status and wished to gain weight, characterizing self- image distortion. Only $12.1 \%$ of normal weight adolescents were satisfied with their shape. About $71 \%$ of obese girls wished to lose weight, while $30.4 \%$ of overweight girls underestimated their actual nutritional status and wished to gain weight. These results showed a self-image distortion (Figure 2).

The prevalence of body dissatisfaction (overestimated or underestimated weight perception) was $76.5 \%$. Body image dissatisfaction was significantly associated to nutritional status $(p<0.001)$, WC $(p<0.001)$, WHR $(p<0.001)$ (Table 1). Adolescents with normal weight reported misperception of their body (underestimated weight perception) more frequently than those with overweight and obese. It is noteworthy that $42.5 \%$ of obese adolescents are satisfied with their weight. More than forty percent of adolescents that overestimated weight perception presented abdominal obesity (WC and WHR).

Body satisfaction assessed by body areas was associated with gender $(p=0.01)$, socioeconomic level $(p=0.03)$, and WHR ( $p=0.01$ ) (Table 2). Girls showed greater body dissatisfaction $(72.7 \%)$ when compared to boys $(27.3 \%)$. Adolescents from low income families (class C2) showed the highest frequency of dissatisfaction. Body satisfaction was higher (82.7\%) among adolescents with no cardiovascular risk. In multiple logistic regression models the only variable that was associated with body dissatisfaction was the economic level. Adolescents from higher income families (C1-B2) were less likely to report body dissatisfaction (data not shown).

Self-perceived body image was associated with nutritional status, WHR, and gender. Overweight and obese adolescents were less likely to wish to gain weight when compared to normal weight. In addition, adolescents with abdominal obesity (WHR) and female adolescents were more likely to wish to lose weight (Table 3).

\section{Discussion}

In our study seven out of ten boys with normal weight underestimated or overestimated their current nutritional status, while more than eight out of ten girls showed misperception about their nutritional status. We observed that girls were significantly more likely to desire to lose weight, and those with abdominal obesity, while adolescents with overweight and obesity were less likely to desire to gain weight.

Body satisfaction assessed by body areas was higher among boys and among adolescents without abdominal obesity. In addition, $22 \%$ of adolescents reported dissatisfaction with their body shape (assessed by body areas), an observation that was significantly more frequent among girls, and those who were from low income households (C2 class).

Given that self-perception of body image is very relevant for general and psychological health, studies have been addressing this issue, including in young people from developing countries.

Recent nationwide study conduct with 71,740 Brazilian adolescents aged 12-17 years showed a prevalence of dissatisfaction with body weight of $45 \%$. This study also revealed that the chance to present a positive screening for mental disorders was higher among adolescents with body image misperception and those with dissatisfaction about their weight. 25

Another study conducted with Brazilian adolescents observed that mental disorders such as depressive non-psychotics symptoms, anxiety and somatic complaints were more frequent among youngsters dissatisfied with their body shape, with a higher prevalence among adolescents desiring to gain weight. 26

The greater dissatisfaction with the weight among girls and those from low income families observed in this study is similar to other studies. 25,26 In fact, the increased adiposity during puberty may be the reason for higher dissatisfaction among girls compared to boys. Furthermore, adolescents are increasingly vulnerable to the pressures of perfect body shapes to fit and feel belonging to the environment in which they are inserted. Body reference image commonly used in mass media may affect how youngsters perceive themselves, contributing to the greater dissatisfaction with the body shape.

The results from the National Survey of School Health (Pesquisa Nacional de Saúde do Escolar [PeNSE]), across-sectional school-based study showed that about $84 \%$ of Brazilian youngsters considered their body image to be important or very important. In addition, for adolescents, body image is seen as a factor of self-acceptance. ${ }^{27}$ Laus et al. ${ }^{28}$ point out that girls press harder to achieve a lean body shape. While the desire for larger silhouettes among boys may be linked to the idea of acquiring more muscle mass, athletic bearing and being a synonym of strength. 29 

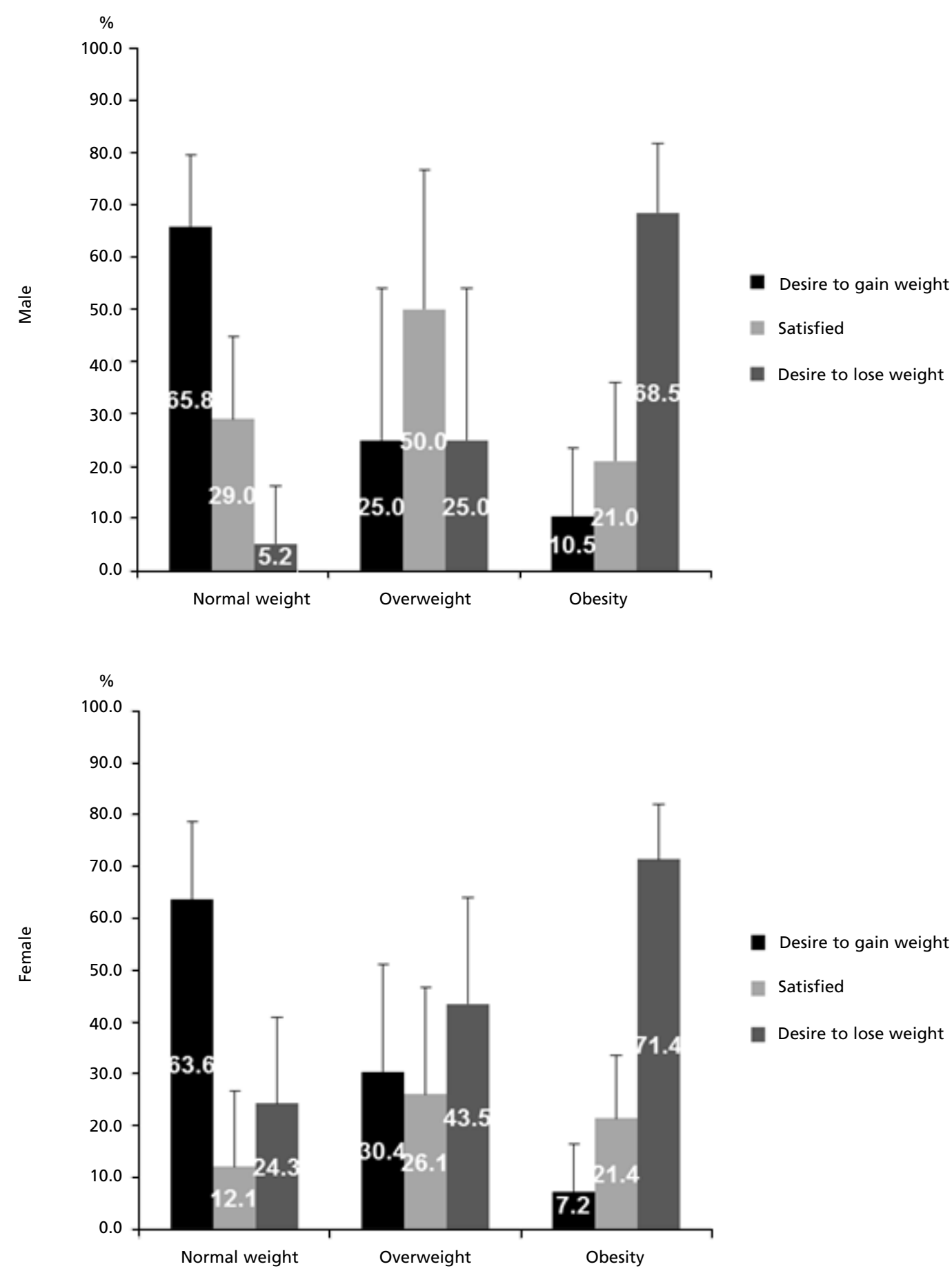
Table 1

Body's dissatisfaction according to sociodemographic variables, anthropometric indicators and sexual maturation.

\begin{tabular}{|c|c|c|c|c|c|c|c|}
\hline \multirow[t]{2}{*}{ Variables } & \multicolumn{2}{|c|}{$\begin{array}{l}\text { Underestimated weight } \\
\text { perception }(\mathrm{N}=64)\end{array}$} & \multicolumn{2}{|c|}{$\begin{array}{l}\text { Satisfied } \\
(\mathrm{N}=47)\end{array}$} & \multicolumn{2}{|c|}{$\begin{array}{l}\text { Overestimated weight } \\
\text { perception }(\mathrm{N}=89)\end{array}$} & \multirow[t]{2}{*}{$p$} \\
\hline & $\mathrm{n}$ & $\%$ & $n$ & $\%$ & $n$ & $\%$ & \\
\hline Gender & & & & & & & $0.06 *$ \\
\hline Male & 32 & 50.0 & 25 & 53.2 & 31 & 34.8 & \\
\hline Female & 32 & 50.0 & 22 & 46.8 & 58 & 65.2 & \\
\hline Race/Ethnicity & & & & & & & $0.74 *$ \\
\hline White & 13 & 20.3 & 8 & 17.0 & 23 & 25.8 & \\
\hline Black & 17 & 26.6 & 17 & 36.2 & 23 & 25.8 & \\
\hline Brown & 30 & 46.8 & 19 & 40.4 & 35 & 39.4 & \\
\hline Others & 4 & 6.3 & 3 & 6.4 & 8 & 9.0 & \\
\hline Age range (years) & & & & & & & $0.81^{\dagger}$ \\
\hline $10-14$ & 55 & 86.0 & 42 & 89.4 & 80 & 89.9 & \\
\hline $15-18$ & 9 & 14.0 & 5 & 10.6 & 9 & 10.1 & \\
\hline Economic class $\ddagger$ & & & & & & & $0.08^{+}$ \\
\hline$D-E$ & 20 & 31.2 & 12 & 25.5 & 21 & 23.9 & \\
\hline $\mathrm{C} 2$ & 29 & 45.3 & 27 & 57.4 & 36 & 40.9 & \\
\hline C1-B2 & 15 & 23.5 & 8 & 17.1 & 31 & 35.2 & \\
\hline Nutritional status & & & & & & & $<0.0011^{\dagger}$ \\
\hline Normal weight & 46 & 71.8 & 15 & 32.0 & 10 & 11.2 & \\
\hline Overweight & 10 & 15.7 & 12 & 25.5 & 13 & 14.6 & \\
\hline Obese & 8 & 12.5 & 20 & 42.5 & 66 & 74.2 & \\
\hline Abdominal obesity (WC) & & & & & & & $<0.001 *$ \\
\hline No & 61 & 95.3 & 39 & 83.0 & 48 & 54.0 & \\
\hline Yes & 3 & 4.7 & 8 & 17.0 & 41 & 46.0 & \\
\hline Abdominal obesity (WHR) & & & & & & & $<0.001 *$ \\
\hline No & 63 & 98.4 & 44 & 93.6 & 50 & 56.2 & \\
\hline Yes & 1 & 1.6 & 3 & 6.4 & 39 & 43.8 & \\
\hline
\end{tabular}

${ }^{*}$ Chi-square test; + linear trend test; $¥$ Missing=1. 
Table 2

\begin{tabular}{|c|c|c|c|c|c|}
\hline \multirow[t]{2}{*}{ Variables } & \multicolumn{2}{|c|}{$\begin{array}{c}\text { Satisfied } \\
\text { Score }>45(N=156)\end{array}$} & \multicolumn{2}{|c|}{$\begin{array}{c}\text { Dissatisfied } \\
\text { Score } \leq 45(N=44)\end{array}$} & \multirow[t]{2}{*}{$p$} \\
\hline & $\mathrm{n}$ & $\%$ & $\mathrm{n}$ & $\%$ & \\
\hline Gender & & & & & 0.01 * \\
\hline Male & 76 & 48.7 & 12 & 27.3 & \\
\hline Female & 80 & 51.3 & 32 & 72.7 & \\
\hline Race/Ethnicity & & & & & $0.05 *$ \\
\hline White & 35 & 22.4 & 9 & 20.4 & \\
\hline Black & 49 & 31.4 & 8 & 18.2 & \\
\hline Brown & 64 & 41.0 & 20 & 45.4 & \\
\hline Others & 8 & 5.2 & 7 & 16.0 & \\
\hline Age range (years) & & & & & $0.30^{+}$ \\
\hline $10-14$ & 140 & 89.8 & 37 & 84.0 & \\
\hline $15-18$ & 16 & 10.2 & 7 & 16.0 & \\
\hline Economic class & & & & & $0.03^{\dagger}$ \\
\hline$D-E$ & 37 & 26.9 & 16 & 36.4 & \\
\hline $\mathrm{C} 2$ & 71 & 45.8 & 21 & 47.7 & \\
\hline $\mathrm{C} 1-\mathrm{B} 2$ & 47 & 30.3 & 7 & 15.9 & \\
\hline Nutritional status & & & & & $0.61^{\dagger}$ \\
\hline Normal weight & 56 & 36.0 & 15 & 34.1 & \\
\hline Overweight & 29 & 18.5 & 6 & 13.6 & \\
\hline Obese & 71 & 45.5 & 23 & 52.3 & \\
\hline Abdominal obesity (WC) & & & & & $0.07 *$ \\
\hline No & 120 & 77.0 & 28 & 63.7 & \\
\hline Yes & 36 & 23.0 & 16 & 36.3 & \\
\hline Abdominal Obesity (WHR) & & & & & 0.01 * \\
\hline No & 129 & 82.7 & 28 & 63.7 & \\
\hline Yes & 27 & 17.3 & 16 & 36.3 & \\
\hline
\end{tabular}

*Chi-square test; ${ }^{\star}$ Linear trend test.

Table 3

Multinomial logistic regression analysis of variables associated with self-perceived body image.

\begin{tabular}{|c|c|c|c|c|}
\hline \multirow[t]{3}{*}{ Variables } & \multicolumn{2}{|c|}{ Desire to gain weight $(\mathrm{N}=64)$} & \multicolumn{2}{|c|}{ Desire to lose weight $(\mathrm{N}=89)$} \\
\hline & Crude analysis & Adjusted analysis & Crude analysis & Adjusted analysis \\
\hline & $O R *(C 195 \%)$ & OR $(\mathrm{Cl} 95 \%)$ & $\mathrm{OR}(\mathrm{Cl} 95 \%)$ & OR $(\mathrm{Cl} 95 \%)$ \\
\hline \multicolumn{5}{|l|}{ Nutritional status } \\
\hline Normal weight & 1 & 1 & 1 & 1 \\
\hline Overweight & $0.27(0.10-0.77)$ & $0.25(0.09-0.73)$ & $1.62(0.53-4.98)$ & $1.35(0.43-4.27)$ \\
\hline Obese & $0.13(0.04-0.36)$ & $0.14(0.04-0.45)$ & $4.95(1.92-12.71)$ & $2.64(0.91-7.68)$ \\
\hline \multicolumn{5}{|c|}{ Abdominal Obesity (WHR) } \\
\hline No & 1 & 1 & 1 & 1 \\
\hline Yes & $0.233(0.023-2.312)$ & $1.25(0.07-21.99)$ & $11.44(3.30-39.62)$ & $26.57(3.98-177.18)$ \\
\hline \multicolumn{5}{|l|}{ Gender } \\
\hline Male & 1 & - & 1 & - \\
\hline Female & $1.13(0.53-2.41)$ & $1.43(0.62-3.28)$ & $2.12(1.03-4.36)$ & $2.65(1.16-6.05)$ \\
\hline
\end{tabular}

WHR= Waist-height ratio; * Multinomial logistic regression. 
The body image distortion when compared to the actual nutritional status observed in our study is in accordance with national and international findings. 29,30 This distortion may be linked, again, to the influence that media, family, and society in general exert in determining appropriate parameters. In addition, since adolescence is a phase of constant morphological and psychological changes, it may be that the adolescent sees body changes in a more intense way than in fact happened. Although some studies used different instruments to evaluate body dissatisfaction, the present study found similar values to those in the literature. $27-30$

Our study has some limitations that must be mentioned. The cross-sectional design does not allow the establishment of cause-effect relationship. Another limitation is the fact that it is a convenience sample, which requires caution in interpreting the results. The high percentage of adolescents' refusals to participate in the study may also represent bias, although the population served by the project is homogeneous in relation to sociodemographic characteristics. In addition, the size of the final sample made it difficult to identify associations with some variables. Finally, some variables that may influence the self-perceived body image were not included in the study, such as physical activity, time of exposure to the screen, possession of a cell phone with access to internet and use of social media.

The strength of this study was the assessment of body satisfaction by body areas, since few studies have investigated body dissatisfaction considering different body areas. The measurement of anthropometric data was also performed by trained interviewers using standardized protocols.

Our results revealed an important distortion and dissatisfaction with body shape especially among girls, overweight/obese adolescents with abdominal obesity. These findings are important to subsidize

\section{References}

1. Silva DAS, Nahas MV, de Sousa TF, Del Duca GF, Peres KG. Prevalence and associated factors with body image dissatisfaction among adults in southern Brazil: A population-based study. Body Image. 2011; 8: 427-31.

2. Silva D, Ferriani L, Viana MC. Depression, anthropometric parameters, and body image in adults: a systematic review. Rev Assoc Med Bras. 2019; 03; 65 (5): 731-8.

3. Thompson JK, van den Berg P. Measuring body image attitudes among adolescents and adults. In: Cash TF, Pruzinsky T, editors. Body images: A handbook of theory, research and clinical practice. New York: Gillford; 2002. p.142-53. actions that deal with the issue of acceptance of selfimage, thus preventing more serious disorders that may directly affect health and well-being of young people.

Government measures to prevent the development and worsening of body image dissatisfaction and to correct misperceptions regarding body image should be encouraged,involving the promotion of healthy body image perception and healthy methods to obtain the correct body weight, such as exercise, healthy diet and reducing media exposure and indoor time to less than 2 hours per day. These measures should be focused on school environments and primary care.

Prospective studiesare required including representative samples of this age group, especially if we consider that cultural and economic variables play an important role in body image perception. Furthermore, other data that may also interfere with self-perceived body image such as behavioral variables and presence of psychological problems secondary to body image dissatisfaction must be included.

\section{Acknowledgements}

We acknowledge the contributions of the coordination team, parents and guardians and to the adolescents of the Non-Governmental Organization.

\section{Author's contribution}

Justino MIC: data collection, interpretation of the data and drafting of the manuscript. Enes CCE: analysis of the data, interpretation of the data and critical revision of the manuscript. Nucci LB: analysis of the data and drafting of the manuscript. All authors approved the final version of the article.

4. Ricciardelli LA, Mccabe MP, Banfield S. Sociocultural influences on body image and body change methods. J Adolesc Health. 2000; 26:3-4.

5. Brumberg JJ. The body project: An intimate history of American girls. New York: Vintage Books; 1998.

6. Hargreaves DA, Tiggemann M. Muscular ideal media images and men's body image: social comparison processing and individual vulnerability. Psychol Men Masc. 2009; 10: 109-19

7. Stice E, Marti CN, Durant S. Risk factors for onset of eating disorders: evidence of multiple risk pathways from 
an 8-year prospective study. Behav Res Ther. 2011; 49: 622-7.

8. Lynch E, Liu K, Spring B, Hankinson A, Wei GS, Greenland P. Association of ethnicity and socioeconomic status with judgments of body size: the Coronary Artery Risk Development in Young Adults (CARDIA) Study. Am J Epidemiol. 2007; 165: 1055-62.

9. Neighbors LA, Sobal J. Prevalence and magnitude of body weight and shape dissatisfaction among university students Eat Behav. 2007; 8 (4): 429-39.

10. O'Dea JA. Gender, ethnicity, culture and social class influences on childhood obesity among Australian schoolchildren: implications for treatment, prevention and community education. Health Soc Care Community. 2008; 16 (3): 282-90

11. Voelker DK, Reel JJ, Greenleaf C. Weight status and body image perceptions in adolescents: current perspectives. Adolesc Health Med Ther. 2015; 6: 149-58.

12. Lo WS, Ho SY, Mak KK, Lai HK, Lai YK, Lam TH. Weight misperception and psychosocial health in normal weight Chinese adolescents. Int J Pediatr Obes. 2011; 6: e381-9.

13. Toral N, Slater B, Silva MV. Consumo alimentar e excesso de peso de adolescentes de Piracicaba, São Paulo. Rev Nutr. 2007; 20 (5): 449-59.

14. Stunkard A, Sorensen T, Schlusinger F. Use of Danish adoption register for the study of obesity and thinness. Res Publ Assoc Res Nerv Ment Dis. 1983; 60: 115-20.

15. Cortes MG, Meireles AL, Friche AAL, Caiaffa WT, Xavier CC. O uso de escalas de silhuetas na avaliação da satisfação corporal de adolescentes: revisão sistemática da literatura. Cad Saúde Pública. 2013; 29 (3): 427-44.

16. Brown TA, Cash TF, Mikulka PJ. Attitudinal body-image assessment: factor analysis of the body-self relations questionnaire. J Pers Assess. 1990; 55 (1-2): 135-44

17. Loland NW. Body image and physical activity. A survey among Norwegian men and woman. Int J Sport Psychol. 1998; 29: 339-65.

18. Lohman TG, Roche AF, Martorell R. Anthropometric Standardization Reference Manual. 1 ed. Illinois: Human Kinetics Books; 1988.

19. de Onis M, Onyango AW, Borghi E, Siyam A, Nishida C, Siekmann J. Development of a WHO growth reference for school-aged children and adolescents. Bull World Health Org. $2007 ; 85$ (9): 660-7
20. Taylor RW, Jones IE, Williams SM, Goulding A. Evaluation of waist circumference, waist- to-hip ratio, and the conicity index as screening tools for high trunk fat mass, as measured by dual-energy X-ray absorptiometry, in children aged 3-19 y. Am J Clin Nutr. 2000; 72 (2): 490-5.

21. Li C, Ford ES, Mokdad AH, Cook S. Recent trends in waist circumference and waist-height ratio among US children and adolescents. Pediatrics. 2006; 118 (5): 1390-8.

22. Marshall WA, Tanner JM. Variations in pattern of pubertal changes in girls. Arch Dis Child. 1969; 44 (235): 291-303.

23. Marshall WA, Tanner JM. Variations in pattern of pubertal changes in boys. Arch Dis Child. 1970; 45 (239): 13-23.

24. ABEP (Associação Brasileira de Empresas de Pesquisa). Critério Brasil 2015 e atualização da distribuição de classes para 2016. [acesso 20 nov 2017]. Disponível em: www.abep.org/Servicos/Download.aspx?id=09

25. Moehlecke M, Blume CA, Cureau FV, Kieling C, Schaan BD. Self-perceived body image, dissatisfaction with body weight and nutritional status of Brazilian adolescents: a nationwide study. J Pediatr (Rio J). 2020; 96: 76-83.

26. Pinheiro KA, Horta BL, Pinheiro RT, Horta LL, Terres NG, Silva R. Common mental disorders in adolescents: a population based cross-sectional study. Rev Bras Psiquiatr. 2007; 29: 241-5.

27. IBGE (Instituto Brasileiro de Geografia e Estatística). Pesquisa Nacional de Saúde do Escolar 2015. Rio de Janeiro; 2016. [acesso 28 Out 2017]. Disponível em: https://biblioteca.ibge.gov.br/visualizacao/livros/liv97870.p df

28. Laus MF, Miranda VP, Almeida SS, Braga TMC, Ferreira ME. Geographic location, sex and nutritional status play an important role in body image concerns among Brazilian adolescents. J Health Psychol. 2013; 18 (3): 332-8.

29. Felden EPG, Claumann GS, Sacomori C, Daronco LS, Cardoso FL, Pelegrini A. Sociodemographic factors and body image among high school students. Ciên Saúde Coletiva. 2015; 20 (11): 3329-37.

30. Amaral ACS, Ferreira MEC. Body dissatisfaction and associated factors among Brazilian adolescents: A longitudinal study. Body Image. 2017; 22: 32-8.

Received on March 6, 2019

Final version presented on March 12, 2020

Approved on June 26, 2020 